\title{
Salmonella Typhimurium enolase-like membrane protein is recognized by antibodies against human enolase and interacts with plasminogen
}

\author{
Paweł Sereke, ${ }^{1, A-F}$, Iwona Bednarz-Misa ${ }^{1, A, C-F}$, Jadwiga Pietkiewicz ${ }^{1, C, E}$, Bartłomiej Dudek ${ }^{2, C, E}$, \\ Magdalena Mierzchała-Pasierb ${ }^{1, D, E}$, Katarzyna Jermakow ${ }^{3, B}$, Marek Drab ${ }^{4, B}$, Andrzej Gamian ${ }^{1,5, E, F}$ \\ ${ }^{1}$ Department of Medical Biochemistry, Wroclaw Medical University, Poland \\ ${ }^{2}$ Department of Microbiology, Faculty of Biological Sciences, University of Wrocław, Poland \\ ${ }^{3}$ Department of Microbiology, Wroclaw Medical University, Poland \\ ${ }^{4}$ Unit of Nano-Structural Bio-Interactions, Hirszfeld Institute of Immunology and Experimental Therapy, Polish Academy of Sciences, Wrocław, Poland \\ ${ }^{5}$ Medical Microbiology Laboratory, Hirszfeld Institute of Immunology and Experimental Therapy, Polish Academy of Sciences, Wrocław, Poland \\ A - research concept and design; B - collection and/or assembly of data; C - data analysis and interpretation; \\ $D$ - writing the article; $E$ - critical revision of the article; $F$ - final approval of the article
}

Address for correspondence

Paweł Serek

E-mail: pawel.serek@umed.wroc.pl

\section{Funding sources}

The project was financed by the National Science Centre (Poland) grant No. DEC-2015/17/N/NZ6/02148.

Conflict of interest

None declared

Received on July 1, 2020

Reviewed on July 12, 2020

Accepted on 0ctober 8, 2020

Published online on November 27, 2020

Cite as

Serek P, Bednarz-Misa I, Pietkiewicz J, et al. Salmonella Typhimurium enolase-like membrane protein is recognized by antibodies against human enolase and interacts with plasminogen. Adv Clin Exp Med. 2020;29(12):1433-1441. doi:10.17219/acem/128233

DOI

10.17219/acem/128233

Copyright

Copyright by Author(s)

This is an article distributed under the terms of the

Creative Commons Attribution 3.0 Unported (CC BY 3.0)

(https://creativecommons.org/licenses/by/3.0/)

\begin{abstract}
Background. Enolase is generally known as the glycolytic pathway enzyme present in the cytoplasm of eukaryotic cells and in some microorganisms. In human cells, it is also a component of cell surface membranes, where it functions as a human plasminogen receptor.

Objectives. The study aimed to purify Salmonella enterica serovar Typhimurium cytosolic enolase and obtain the antibodies against this protein; to identify enolase on the surface of bacteria; and to find cross-reactivity and plasminogen binding properties.

Material and methods. Cytosolic enolase from S. Typhimurium was purified using a five-step preparation method. Anti-cytosolic enolase antibodies combined with scanning electron microscopy (SEM) allowed us to detect enolase on the surface of intact $S$. Typhimurium cells. The binding of plasminogen to surface enolase and the cross-reactivity of this protein with antibodies against human enolases were tested with western blot.

Results. Antibodies against human a- and $\beta$-enolases cross-reacted with S. Typhimurium membrane protein, the identity of which was further confirmed using a mass spectrometry analysis of enolase tryptic peptides. The enolase form bacterial membrane also bound plasminogen.

Conclusions. The cross-reactivity of membrane enolase with antibodies against human enolases suggests that this bacterium shares epitopes with human proteins. Surface exposition of enolase and the demonstrated affinity for human plasminogen indicates that Salmonella membrane enolase could play a role in the interaction of S. Typhimurium with host cells.
\end{abstract}

Key words: membrane proteins, Salmonella, Typhimurium, enolase 


\section{Introduction}

The World Health Organization (WHO) reported that every year about 600 million people fall ill after eating contaminated food and 420000 die, making it the leading cause of mortality worldwide. In addition, children under 5 years of age carry $40 \%$ of the foodborne disease burden, with 125000 deaths every year. Streptococci, staphylococci and Enterobacteriaceae are major contributors to bacterial disease. ${ }^{1,2}$

Salmonella spp. are Gram-negative, rod-shaped bacteria that belong to the Enterobacteriaceae family. There are 2 species within the genus Salmonella: S. enterica and S. bongori. Salmonella enterica is a pathogenic bacteria and is further divided into more than 2500 serotypes. ${ }^{3}$ Salmonella enteritidis and $S$. Typhimurium are 2 of the most common clinical serotypes of salmonellosis agents isolated worldwide. ${ }^{4}$

There are 2 main clinical types of Salmonella infection. The first one is caused by non-typhoidal Salmonella strains. The symptoms of this type are limited to the gastrointestinal tract and typically include acute gastritis and enteritis, high fever, spasmodic abdominal pain, and bloody mucus diarrhea. The $2^{\text {nd }}$ clinical type is typhoid fever, caused by Salmonella typhi infection, and resulting in a systemic inflammatory response, usually requiring antibiotic treatment. For both, the first phase in the infection process is bacterial adhesion to the intestinal epithelium, which impedes the host's ability to naturally remove the bacterium from the digestive tract. This allows the bacteria to survive, multiply and colonize the host environment. ${ }^{5}$

Outer membrane proteins (OMPs) play a crucial role in the infection and colonization processes. They participate in bacterial contact with host tissues, in initiating the process of degradation of the host tissue and in stimulating the development of infections. They are also important factors in bacterial adaptation to the host environment. ${ }^{6,7}$

Enolase (Enzyme Commission (EC) 4.2.1.11) is a glycolytic enzyme found in the cytoplasm of eukaryotes and prokaryotes. ${ }^{8}$ It is also an external component of cell membranes in the epithelium and endothelium, in monocytes, leukocytes and neutrophils. ${ }^{9,10}$ Enolase acts as a receptor for plasminogen, which plays a unique role in the defense system of the human body. ${ }^{8}$ For example, active plasmin degrades fibrin in the process of fibrinolysis, which is critical for maintaining hemostasis. Plasminogen also permits cell migration to areas of inflammation. Interestingly, bacteria also have exposed surface plasminogen binding receptors on their cell surfaces. Plasminogen, once cleaved to become the active form called plasmin, allows bacteria to migrate through host tissues. Another example of such a receptor is the surface enolase-like protein, whose properties were described for Streptococcus pneumoniae. ${ }^{11}$

During inflammation caused by Gram-positive or Gramnegative bacteria, the host develops enolase-targeted antibodies. ${ }^{6,12}$ Since there is greater than $50 \%$ homology among enolases of different species, ${ }^{8}$ the structural similarity between human and bacterial enolase can lead to the phenomenon of molecular mimicry. Molecular mimicry is the mechanism whereby antibodies produced by a host against foreign antigens cause cross-reactivity with epitopes of the host's own protein; this can result in autoimmune diseases. ${ }^{13}$ The presence of anti- $\alpha$-enolase antibodies has been observed in disorders like Behçet's disease, Hashimoto's encephalopathy and Sjögren's syndrome. ${ }^{14-16}$

Since the enolase from Salmonella spp. has not been previously characterized, the purpose of this study was to isolate, purify and perform an immunochemical characterization of the enolase from $S$. Typhimurium bacteria. Deeper insights into the properties of this protein will help to further elucidate its pathogenesis in the development of autoimmune diseases. This paper describes how we identified enolase as a component of $S$. Typhimurium surface proteins and demonstrates the binding of surface enolase to human plasminogen.

\section{Material and methods}

\section{Bacterial strain, media and growth conditions}

Salmonella enterica serovar Typhimurium (Polish Collection of Microorganisms (PCM) 2713) was obtained from the PCM at the Institute of Immunology and Experimental Therapy, Polish Academy of Sciences, Wrocław, Poland. The bacteria were cultured on tryptic soya agar (Graso Biotech, Owidz, Poland) solid media at $37^{\circ} \mathrm{C}$ for $18 \mathrm{~h}$.

\section{Extraction and purification of $S$. Typhimurium cytoplasmic proteins}

Protein extraction was performed according to the method described by Bednarz-Misa et al., ${ }^{17}$ with minor modifications. The bacterial mass was suspended in $10 \mathrm{mM}$ Tris$\mathrm{HCl}, \mathrm{pH} 8.4$ (Sigma-Aldrich, St Louis, USA) with $1 \mathrm{mM}$ $\mathrm{MgSO}_{4}$ (Chempur, Piekary Śląskie, Poland), $1 \%$ glycerol (v/v) (Chempur), 0.5 mM $\beta$-mercaptoethanol (Sigma-Aldrich), and a protease inhibitor cocktail (Merck Millipore, Burlington, USA). The bacterial cells were lysed using the Vibra-Cell YC-130PB ultrasonic processor (Labo-Plus, Warszawa, Poland) at $4{ }^{\circ} \mathrm{C}$ for $30 \mathrm{~min}$, during 40 -second cycles on ice. To remove unbroken cells, the suspension was centrifuged $\left(4000 \times \mathrm{g}, 4^{\circ} \mathrm{C}, 1 \mathrm{~h}\right)$. The collected supernatant was re-centrifuged $\left(100,000 \times \mathrm{g}, 4^{\circ} \mathrm{C}, 1 \mathrm{~h}\right)$ to obtain the cytosolic fraction (supernatant) and the cell membrane fraction (saved for later purification). For the initial removal of unwanted proteins, 3 stages of protein precipitation with increasing ammonium sulfate (Chempur) saturation $(0-30 \%, 30-80 \%$ and $80-100 \%)$ were completed. The $1^{\text {st }}$ purification step was carried out through ion exchange 
chromatography with a strong anionite Sepharose Q Fast Flow column (GE Healthcare, Chicago, USA). The proteins were precipitated with $30-80 \%$ ammonium sulfate and dialyzed into elution buffer $(20 \mathrm{mM}$ Tris- $\mathrm{HCl}, \mathrm{pH} 8.4$, $1 \mathrm{mM} \mathrm{MgSO}_{4}$ and $1 \mathrm{mM} \beta$-mercaptoethanol). The procedure was carried out on the AKTA Explorer 100 GE chromatograph (GE Healthcare). The column was equilibrated with elution buffer and $50 \mathrm{mg}$ of cytosolic protein extract was applied and separated at a flow of $2 \mathrm{~mL} / \mathrm{min}$ in an ionic strength gradient of $1 \mathrm{M} \mathrm{NaCl}$ (Chempur) as follows: 6 column volumes (CVs) elution buffer, $3 \mathrm{CVs} 8 \%$ isocratic gradient, 6 CVs gradient $8-70 \%$, and 5 CVs gradient $100 \%$ to release the remaining proteins from the column. Protein concentration was determined spectrophotometrically at $280 \mathrm{~nm}$. To quantify the enolase, an absorption coefficient of $\mathrm{A} 0.1 \%=0.89$ was used, determined for rabbit muscle enolase at a concentration of $1 \mathrm{mg} / \mathrm{mL} .{ }^{18}$ The enzymatic activity for cytosolic enolase was assessed spectrophotometrically (EnviSense UV-1800; EnviSense, Lublin, Poland) at room temperature (RT) at $240 \mathrm{~nm}$ as an increase in phosphoenolpyruvate (PEP) concentration in the reaction buffer (50 mM imidazole- $\mathrm{HCl}, \mathrm{pH}$ 8.4 (Sigma-Aldrich), $1 \mathrm{mM} \mathrm{MgSO}_{4}, 400 \mathrm{mM} \mathrm{KCl}$ (Chempur) and $1 \mathrm{mM}$ 2-phosphoglyceric acid (2-PGA)). One unit of enolase activity is defined as the amount of protein that under these conditions catalyzes the synthesis of $1 \mu \mathrm{mol}$ of PEP from 2-PGA in 1 min. ${ }^{19}$ The active fractions were eluted from the $20-35 \%$ gradient, and then collected, concentrated and dialyzed into a sodium chloride-free buffer using Centricon 30K filters (Merck Millipore).

The protein fractions collected in the $1^{\text {st }}$ chromatography step (20 mg) were then applied to a Sephadex G-100 column (GE Healthcare). The column was equilibrated with $20 \mathrm{mM}$ Tris- $\mathrm{HCl}$ buffer, $\mathrm{pH} 8.4$ with $300 \mathrm{mM} \mathrm{NaCl}$ (Chempur), $1 \mathrm{mM} \mathrm{MgSO}_{4}$ and $1 \mathrm{mM} \beta$-mercaptoethanol. Chromatographic separation was carried out at a flow of $0.1 \mathrm{~mL} / \mathrm{min}$ on an AKTA Explorer $100 \mathrm{HPLC}$ system (GE Healthcare). The final purification step used preparative electrophoresis on the PrepCell 491 device (Bio-Rad, Hercules, USA). Discontinuous separation was carried out at $280 \mathrm{~V}$ under native conditions in 4\% stacking gel and 10\% separating gel in $25 \mathrm{mM}$ Tris and $192 \mathrm{mM}$ glycine (BioShop Canada Inc., Burlington, Canada), pH 8.3.

\section{Extraction and purification of S. Typhimurium OMPs}

The pellet fraction obtained after centrifugation at $100,000 \times \mathrm{g}$ was used for purification of the OMP. The pellet was washed twice with $20 \mathrm{mM}$ Tris- $\mathrm{HCl}$ buffer, $\mathrm{pH} 7.2$, using a tissue grinder. The suspension was then centrifuged $\left(100,000 \times \mathrm{g}, 4^{\circ} \mathrm{C}, 1 \mathrm{~h}\right)$. The pellet collected at this step was resuspended in $20 \mathrm{mM}$ Tris- $\mathrm{HCl}, \mathrm{pH} 7.4$, and $80 \mathrm{mM}$ CHAPS detergent (BioShop Canada Inc.). Membrane protein extraction was carried out for $30 \mathrm{~min}$ at $4^{\circ} \mathrm{C}$. The suspension was again centrifuged $(100,000 \times \mathrm{g}$, $4^{\circ} \mathrm{C}, 1 \mathrm{~h}$ ) and the supernatant containing the extracted membrane protein was collected. The protein concentration was measured using a bicinchoninic acid (BCA) assay (Thermo Fisher Scientific, Waltham, USA).

For the final purification step the extracted membrane proteins were diluted 1:1 with $\times 2$ Laemmli sample buffer (Bio-Rad) and incubated for $5 \mathrm{~min}$ at $100^{\circ} \mathrm{C}$. The proteins were separated at $200 \mathrm{~V}$ and $1 \mathrm{~mL} / \mathrm{min}$ with the PrepCell 491 device (Bio-Rad) using 10\% and 12\% separating gel in an electrode buffer: $25 \mathrm{mM}$ Tris and $192 \mathrm{mM}$ glycine, 0.5\% SDS, pH 8.3 (Bio-Rad).

All procedures involving animals were in accordance with the ethical standards of Wroclaw Medical University and approved by the Local Ethics Committee for Animal Experiments (approval No. 55/2017).

\section{Preparation of rabbit polyclonal antibodies specific to $S$. Typhimurium cytosolic enolase}

A male New Zealand rabbit weighing $2 \mathrm{~kg}$ was immunized with a total of $1.5 \mathrm{mg}$ of $S$. Typhimurium enolase. The $1^{\text {st }}$ multipoint intradermal injection was performed with $0.5 \mathrm{mg}$ of enolase diluted in $0.5 \mathrm{~mL}$ of phosphate buffered saline (PBS) (BioShop Canada Inc.) mixed with an equal volume of incomplete Freund's adjuvant (Sigma-Aldrich). After 3 weeks, a $2^{\text {nd }}$ immunization was performed in the same way. The $3^{\text {rd }}$ injection of protein was performed after another 3 weeks. Two weeks later, the animal was bled. The collected antisera were filtered and incubated at $56^{\circ} \mathrm{C}$ for $30 \mathrm{~min}$ to inactivate the complement. IgG antibodies were isolated on a Protein A Protein G GraviTrap column (GE Healthcare) according to the manufacturer's instructions.

\section{Electrophoresis and immunoblotting}

The bacterial enolase-like protein was detected with western blot analysis using rabbit anti-cytosolic enolase $S$. Typhimurium antibodies. The $S$. Typhimurium OMP fraction $(10 \mu \mathrm{g})$ obtained during preparative electrophoresis and purified $S$. Typhimurium cytosolic enolase $(10 \mu \mathrm{g})$ were diluted 1:1 with $\times 2$ Laemmli sample buffer containing $5 \%$ 2-mercaptoethanol, followed by denaturation for $5 \mathrm{~min}$ at $95^{\circ} \mathrm{C}$. The samples were resolved with SDS-PAGE electrophoresis ${ }^{20}$ using a $4.5 \%$ stacking gel and a $12 \%$ resolving gel. The proteins were then visualized with Coomassie brilliant blue G-250 (BioShop Canada Inc.) staining or transferred to an Immobilon P membrane (Merck Millipore) for $90 \mathrm{~min}$ at $200 \mathrm{~mA} .{ }^{12}$ The membrane was blocked with $1 \%$ casein blocking buffer (Sigma-Aldrich) at $37^{\circ} \mathrm{C}$ for $1 \mathrm{~h}$. After washing, the membrane was incubated with IgG antibodies obtained from a rabbit immunized with Salmonella cytosolic enolase in TBS-T buffer (20 mM Tris-HCl, pH 7.0, 50 mM $\mathrm{NaCl}, 0.05 \%$ Tween-20 (Sigma-Aldrich), pH 7.0). Unbound antibodies were removed through washing with TBS-T 
buffer. Next, the membrane was incubated with goat antirabbit IgG antibodies (Abcam, Cambridge, UK) conjugated with horseradish peroxidase (HRP) at $37^{\circ} \mathrm{C}$ for $1 \mathrm{~h}$. The western blot was visualized using a colorimetric reaction with substrate 3-amino-9-ethylcarbazole (Sigma-Aldrich).

Immunoblotting with human plasminogen was performed with the $S$. Typhimurium OMP fraction $(10 \mu \mathrm{g})$ obtained during preparative electrophoresis and with purified $S$. Typhimurium cytosolic enolase $(10 \mu \mathrm{g})$. The SDSPAGE, protein transfer and membrane blocking were performed as outlined above. After washing, the membranes were incubated with $20 \mu \mathrm{g}$ of human plasminogen (R\&D Systems, Minneapolis, USA) in TBS buffer $(20 \mathrm{mM}$ Tris- $\mathrm{HCl}, 50 \mathrm{mM} \mathrm{NaCl}, \mathrm{pH} 7.0$ ) at $37^{\circ} \mathrm{C}$ for $1 \mathrm{~h}$, then overnight at $4^{\circ} \mathrm{C}$. Unbound plasminogen was removed through washing with TBS-T buffer. The membranes were then incubated with rabbit anti-human plasminogen antibodies (Abcam) and, after further washing, with HRP goat anti-rabbit IgG antibodies (Abcam). The western blot was visualized using a colorimetric reaction with substrate 3-amino-9-ethylcarbazole (Sigma-Aldrich).

The reactive fraction of OMPs from $S$. Typhimurium was separated by two-dimensional electrophoresis (2-DE), as described earlier. ${ }^{21}$ The OMPs for transfer $(40 \mu \mathrm{g})$ or for silver staining $(20 \mu \mathrm{g})$ were separated with $\mathrm{pH} 4-7$ immobilized $\mathrm{pH}$ gradient strips ( $7 \mathrm{~cm}$, from (Bio-Rad). The $2-\mathrm{DE}$ analysis was carried out with the Mini-PROTEAN ${ }^{\circledR}$ Tetra Cell System (Bio-Rad). Prior to resolving the first dimension, precast IPG strips were rehydrated with $120 \mu \mathrm{L}$ of rehydration buffer (Bio-Rad) for $16 \mathrm{~h}$ at room temperature. Isoelectric focusing (IEF) was conducted through stepwise voltage increases: $250 \mathrm{~V}$ for $20 \mathrm{~min}, 4000 \mathrm{~V}$ for $120 \mathrm{~min}$ (linear) and $4000 \mathrm{~V}$ (rapid) until the total volt-hours reached $14 \mathrm{kVh}$. After IEF separation, the strips were equilibrated in $6 \mathrm{M}$ urea (BioShop Canada Inc.), $375 \mathrm{mM}$ Tris, $\mathrm{pH} 8.8$, $2 \%$ SDS, reduced with $2 \%(\mathrm{w} / \mathrm{v})$ ditiotreitol (DTT) (BioShop Canada Inc.) and alkylated with $135 \mathrm{mM}$ iodoacetamide (Sigma-Aldrich). The IPG strips were then loaded onto a $9-12.5 \%$ gradient polyacrylamide gel $(10 \times 8 \mathrm{~cm}, 1.0 \mathrm{~mm}$ thick) using $0.5 \%$ agarose (Bio-Rad) in the running buffer. Molecular mass standards (Precision Plus Protein ${ }^{\mathrm{TM}}$ Standards; Bio-Rad) were applied at the basic end of the IPG strips. Electrophoresis was performed at $4^{\circ} \mathrm{C}$ with constant power $(1 \mathrm{~W})$. Following separation in the second dimension, the gels were silver stained. ${ }^{22}$ Spot patterns were visualized under white light and photographed using a GelDoc XR camera system (Bio-Rad).

Then 2-DE OMPs were transferred from gel to the Immobilon P membrane as described above. The membranes were blocked with $1 \%$ casein blocking buffer (SigmaAldrich) at $37^{\circ} \mathrm{C}$ for $1 \mathrm{~h}$. After washing, the membranes were incubated with either mouse anti-human $\alpha$-enolase and/ or with anti-human $\beta$-enolase antibodies (both from SantaCruz Biotechnology, Dallas, USA) at $37^{\circ} \mathrm{C}$ for $1 \mathrm{~h}$. Secondary antibody incubation was performed using HRP goat anti-mouse IgG (Novus Biologicals, Centennial, USA) and the proteins were visualized using a colorimetric reaction with substrate 3-amino-9-ethylcarbazole (Sigma-Aldrich).

\section{In-gel protein digestion and mass spectrometry protein identification}

The appropriate protein spot was excised from the gel and analyzed using liquid chromatography coupled with mass spectrometry in the Laboratory of Mass Spectrometry, Institute of Biochemistry and Biophysics, Polish Academy of Sciences (Warszawa, Poland). Samples were subjected to standard trypsin digestion, during which the proteins were reduced with $10 \mathrm{mMDTT}$ for $30 \mathrm{~min}$ at $56^{\circ} \mathrm{C}$, alkylated with iodoacetamide in the dark for $45 \mathrm{~min}$ at room temperature and digested with $10 \mathrm{ng} / \mu \mathrm{L}$ trypsin overnight. The resulting peptide mixtures were concentrated and desalted on a RPC18 pre-column (Waters, Milford, USA) and further peptide separation was achieved on a nano-Ultra Performance Liquid Chromatography (UPLC) RP-C18 column (Waters, BEH130 C18 column, $75 \mu \mathrm{m}$ i.d., 250 mm long; Waters) using a 45-minute linear acetonitrile gradient in the presence of $0.1 \%$ formic acid. The column outlet was directly coupled to the Orbitrap Velos MS ion source (Thermo Electron Corp., San Jose, USA). Mass spectra were obtained with a full scan on an Orbitrap mass analyzer in data dependent acquisition (DDA) mode, followed by MS/MS scans in the ion trap. A blank run to ensure the absence of cross-contamination from previous samples preceded each analysis.

The acquired MS/MS data was pre-processed with Mascot Distiller software v. 2.6 (Matrix Science Ltd., London, UK) and the search was performed using the Mascot Search Engine (Matrix Science Ltd.) against the National Center for Biotechnology Information (NCBI; US National Library of Medicine, Bethesda, USA) NCBInr database (176 222799 sequences; 64 284 901062 residues), with a $S$. Typhimurium filter (101 607 sequences). To reduce mass errors, the peptide and fragment mass tolerance settings were established after a measured mass recalibration, ${ }^{23}$ resulting in a value of $6.5 \mathrm{ppm}$ for parent and $0.01 \mathrm{Da}$ for fragment ions. The rest of the search parameters were as follows: enzyme, trypsin; missed cleavages, 1; fixed modifications, carbamidomethyl $(\mathrm{C})$; variable modifications, oxidation (M); instrument, HCD. The Decoy Mascot functionality was used to keep the false discovery rate (FDR) for peptide identifications below $1 \%$.

\section{Scanning electron microscopy}

To demonstrate the immunostaining pattern of pathogens detected with the polyclonal $S$. Typhimurium cytosolic enolase antibody, cells were further treated with secondary anti-rabbit antibody labelled with $30 \mathrm{~nm}$ colloidal gold. Bacteria treated only with secondary antibodies were used as a control. Scanning electron microscopy (SEM) was processed with low accelerating voltage of the primary beam (low-voltage field-emission SEM - LV-FESEM) without 
any coating of the sample. ${ }^{24}$ The bacterial colonies were stamped with polished silicon chips by pressing the chip against the bacterial colony for $5 \mathrm{~min}$ at room temperature. The samples were fixed with $2.5 \%$ formaldehyde in $100 \mathrm{mM}$ cacodylate buffer at $4^{\circ} \mathrm{C}$ for $30 \mathrm{~min}$, and then washed in water and dehydrated in a series of methanol steps (25-50-75-100\%), each lasting $1 \mathrm{~h}$ at $4^{\circ} \mathrm{C}$. The samples went through critical point drying with methanol, undergoing an exchange for liquid $\mathrm{CO}_{2}$ in an automatized critical point dryer (CPD300 AUTO; Leica Microsystems, Vienna, Austria) and were imaged with a cross-beam scanning electron microscope equipped with a Schottky field-emission cathode (Auriga 60; Carl Zeiss, Oberkochen, Germany) at $1.5 \mathrm{kV}$ accelerating voltage. A non-coating approach was implemented within the LV-FESEM mode, whose low energies allow efficient interaction of electrons with native elements of the biological sample (typically low Z-number atoms). We applied the low-energy loss electron principle to generate a highly resolved chemical contrast, as we described in detail previously. ${ }^{25}$ Images were acquired with an Everhart-Thornley electron detector (SE2 secondary electrons), the in-lens electron detector (SE1 secondary electrons) and the energy-selective back-scattered electron detector (EsB) directly from the sample surfaces with no coating or contrasting applied. ${ }^{24,25}$ The EsB detector grid potential was set to $1200 \mathrm{~V}$, and brightness and contrast were adjusted to allow a distinction between the substratum (a polished silicon chip with a grey appearance), the biological sample (bacteria and their appendages, dark in appearance) and the nano-gold label (bright appearance). The sample imaging was performed in a dual-view mode enabling correlative imaging between 2 channels in parallel with pixel-to-pixel correlative accuracy.

\section{Results}

\section{Purification of cytosolic enolase from \\ S. Typhimurium}

The method of $S$. Typhimurium enolase purification involved sonication, precipitation with ammonium sulfate, ion-exchange chromatography, gel filtration, and preparative electrophoresis. Preparative electrophoresis for the separation of cytosolic proteins permitted the purification of enzymatically active enolase with electrophoretic

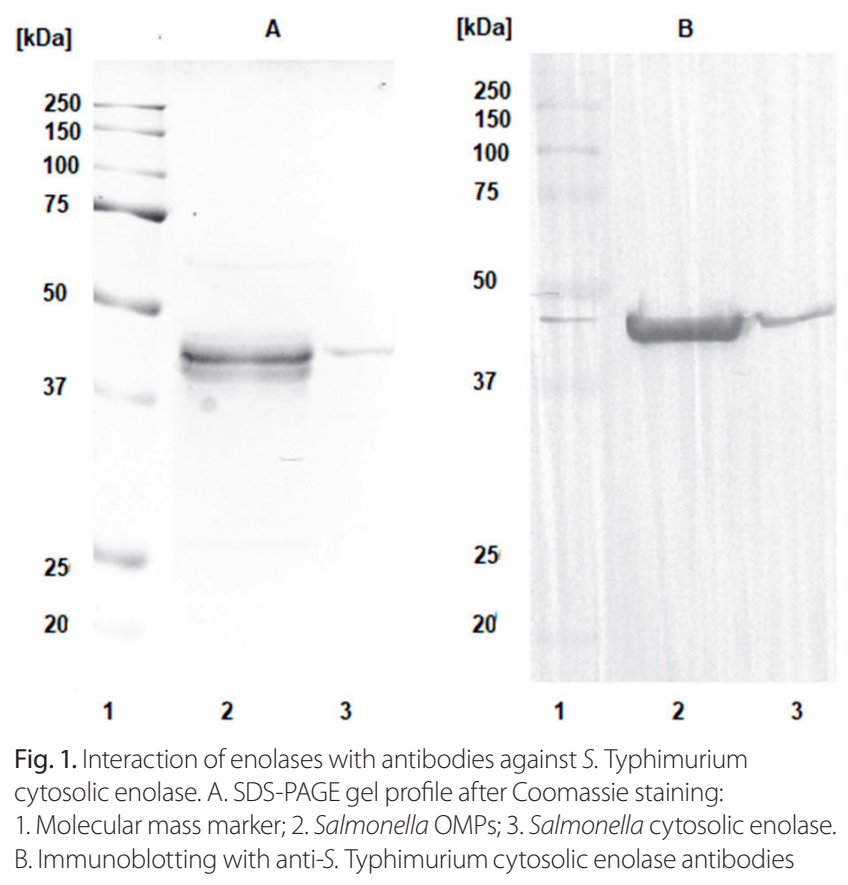

mobility at about $45 \mathrm{kDa}$. Row 3 in Fig. $1 \mathrm{~A}$ shows the homogeneity level of enolase that was used for rabbit immunization. The purification process resulted in pure protein with 15\% efficiency (Table 1).

\section{Purification of the enolase-like membrane protein from $S$. Typhimurium}

The OMPs were extracted using CHAPS detergent and $4.4 \mathrm{mg}$ was obtained as soluble micelles from $10 \mathrm{mg}$ of membrane protein extract. The purification of enolaselike protein was performed using preparative SDS-PAGE with continuous elution. The OMPs with a molecular mass of 45-47 kDa were purified from the protein extract. The fraction of OMPs reactive with antibodies against $S$. Typhimurium cytosolic enolase (Fig. 1A, row 2) was selected for further testing on 2-DE.

\section{Antibodies against S. Typhimurium cytosolic enolase cross-react with S. Typhimurium OMPs}

Human $\alpha$-enolase and $\beta$-enolase, like the OMPs and cytosolic enolases of $S$. Typhimurium used in the immunoblotting, reacted with antibodies from rabbit serum

Table 1. Purification of cytosolic enolase from S. Typhimurium

\begin{tabular}{|l|c|c|c|}
\multicolumn{1}{|c|}{ Fractions } & Total protein [mg] & Total activity [IU] & Specific activity [IU/mg] \\
\hline Crude extract & 717.7 & 409 & 0.57 \\
\hline (30-80\%) $\left(\mathrm{NH}_{4}\right)_{2} \mathrm{SO}_{4}$ & 435.7 & 314 & 0.72 \\
\hline Q Sepharose Fast Flow & 102.04 & 202 & 1.98 \\
\hline Sephadex G-100 & 17.88 & 123 & 6.88 \\
\hline PrepCell & 2.94 & 61 & 20.9 \\
\hline
\end{tabular}


immunized by cytosolic enolase (Fig. 1B). This observation corroborated that the 2 enolases could have similar antigenic properties.

\section{S. Typhimurium enolase-like membrane protein binds to plasminogen}

The OMPs that exhibited reactivity with anti-S. Typhimurium cytosolic enolase polyclonal antibodies also bound human plasminogen (Fig. 2A,B, row 2). However, no such interaction was observed for Salmonella cytosolic enolase (Fig. 2A,B, row 3). Denatured Salmonella cytosolic enolase showed no plasminogen binding capacity.

A

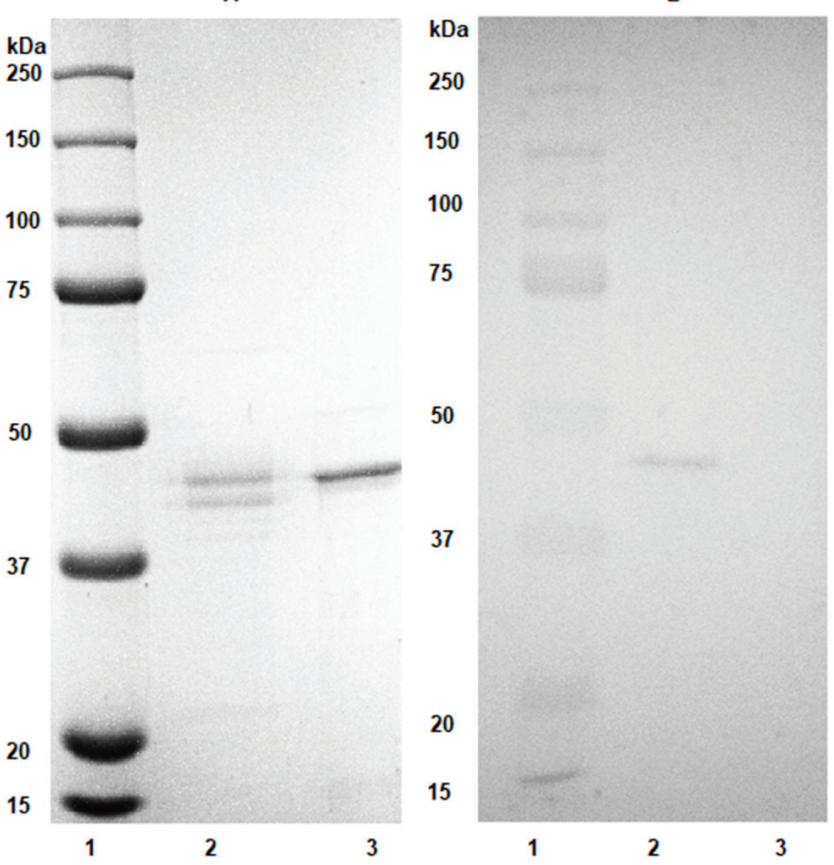

Fig. 2. Interaction of human plasminogen with membrane proteins and cytosolic enolase from S. Typhimurium. A. SDS-PAGE gel profile after Coomassie staining: 1. Molecular mass marker; 2 . Salmonella OMPs; 3. Salmonella cytosolic enolase. B. Immunoblotting with human plasminogen

\section{Enolase-like membrane protein from}

\section{$S$. Typhimurium reacts with antibodies against human enolases}

The OMPs exhibiting reactivity with anti-S. Typhimurium cytosolic enolase polyclonal antibodies were separated using 2-DE, and they bound antibodies against human $\alpha$ - and $\beta$-enolase. This revealed the serological similarity of epitopes of the enolase-like protein from Salmonella and from humans. The results of the immunoblotting assay are shown in Fig. 3B and 3C. Protein spots of interest were subsequently identified using liquid chromatography coupled with mass spectrometry. The OMP identification was achieved using the bioinformatics platform Mascot Search Engine to search the NCBInr database. The protein identified was "Multispecies enolase (Salmonella); molecular weight: $45.627 \mathrm{kDa}$, pI: 5.25 Average sequence coverage: $65 \%$ ", score: 2625 .

\section{Scanning electron microscopy}

Immunoelectron microscopy using anti-S. Typhimurium cytosolic enolase polyclonal antibodies confirmed the cell surface localization of enolase. On the outer membrane of the intact bacterial cell, reactivity was observed mostly at the flagella (Fig. 4A). In contrast, no labelling was observed in the negative control (Fig. 4B).

\section{Discussion}

Salmonella enolase has not previously been isolated and characterized. The procedure established in this study allowed us to obtain highly pure, enzymatically active enolase. The protein was purified and used to develop antibodies, which facilitated identification of the enolaselike protein on the bacterial outer membrane of $S$. Typhimurium. The efficiency of molecular biology methods and the ability to obtain recombinant proteins quickly gives these methods a greater advantage over long purification procedures developed to isolate native proteins.

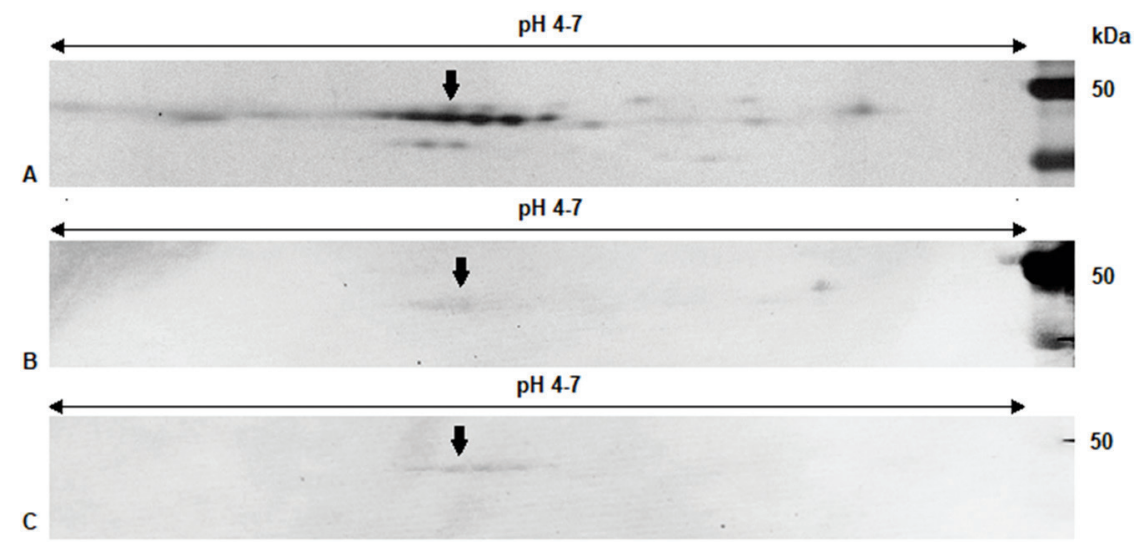

Fig. 3. Interaction of S. Typhimurium membrane proteins with antibodies against human enolases. A. Silver-stained 2-DE profile over $\mathrm{pH}$ 4-7 of S. Typhimurium OMPs isolated with CHAPS detergent after final purification using preparative electrophoresis. B. Immunoblotting of OMPs from S. Typhimurium with antibodies against human a-enolase. C. Immunoblotting of OMPs from S. Typhimurium with antibodies against human $\beta$-enolase. The spot identified by MS as enolase is indicated by the arrow 


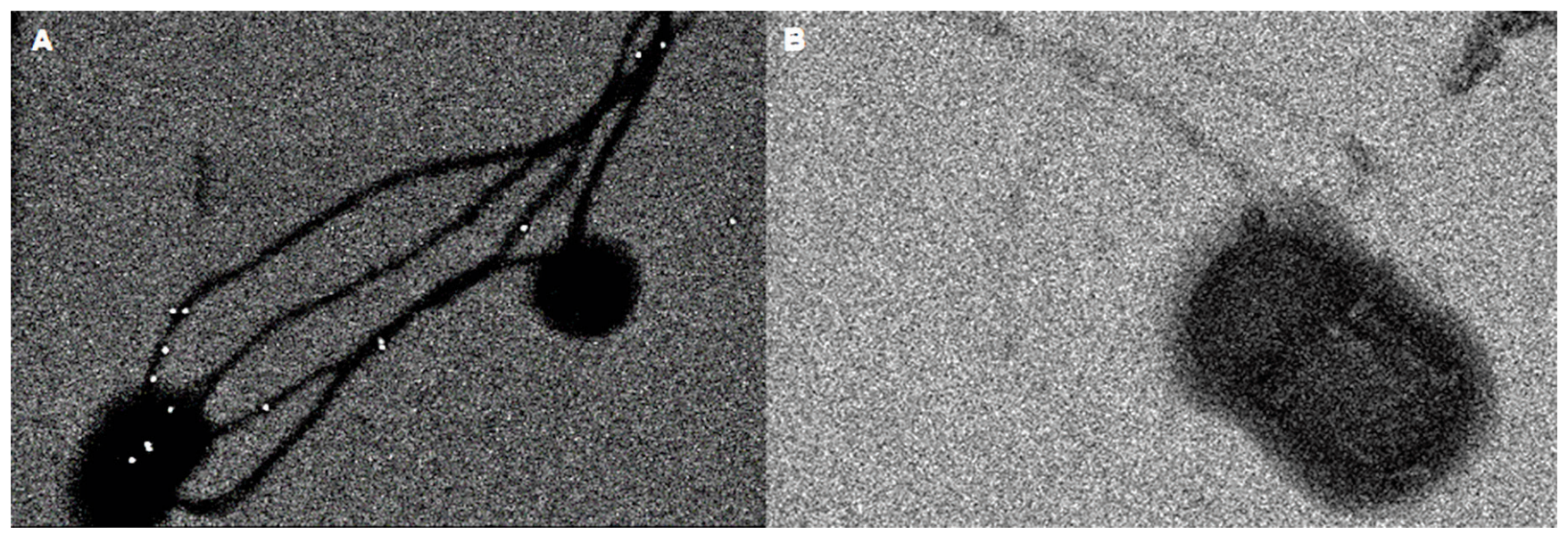

Fig. 4. Scanning electron microscopy localization of surface enolase on whole S. Typhimurium cells. A. Enolase detected with antibodies against bacterial cytosolic enolase and labeled with anti-rabbit antibodies coupled to $30 \mathrm{~nm}$ colloidal gold particles. B. Negative control with anti-rabbit antibodies coupled to $30 \mathrm{~nm}$ colloidal gold particles

Among the first microorganisms for which enolase isolation was described was Gram-positive Brevibacterium fuscum. Purification through salting and ion-exchange chromatography resulted in high protein losses and only $1.2 \%$ protein efficiency. ${ }^{26}$ Chromatography affinity was used for the purification of Streptococcus suis enolase, leveraging the ability of the protein to bind to fibronectin. ${ }^{27}$ Escherichia coli was the first Gram-negative bacterium for which the cytosolic enolase purification procedure was developed. Through desalting and the use of hydrophobic and ion exchange media, the purification of $E$. coli enolase yielded about $17 \%{ }^{28}$ Klebsiella pneumoniae is another species of bacterium of the Enterobacteriaceae family for which an enolase purification procedure has been developed. After precipitation of the bacterial proteins with an $80-100 \%$ range of ammonium sulfate, gel filtration was performed, followed by ion exchange chromatography and preparative electrophoresis. The method developed in our laboratory yielded a 76-fold purification of cytosolic enolase with a total yield of $15 \%$. This shows that preparative electrophoresis can be an effective purification method for an active enolase enzyme. ${ }^{17}$ The continuous development of chromatographic methods and media allowed us to improve the protein purification procedures and to reduce the number of steps. This minimized the loss of the active fraction of the enzyme, thus maintaining its biological properties.

We demonstrated that $S$. Typhimurium membrane proteins with a molecular mass of $45 \mathrm{kDa}$ showed reactivity with antibodies against human $\alpha$ - and $\beta$-enolase, suggesting a serological similarity between epitopes. These observations indicate that Salmonella infections may cause the host immune system to produce antibodies against bacterial enolase and host enolase epitopes, resulting in the development of auto-aggressive diseases. There have been numerous examples of cross-reactivity between human and bacterial enolases. For example, cross-reactivity has been demonstrated between the enolase of the pathogen causing periodontitis (Treponema denticola) and human $\alpha$-enolase. Mice immunized with $T$. denticola enolase induced the production not only of antibodies against T. dentolitica enolase but also of antibodies against human $\alpha$-enolase. ${ }^{29}$ Similarly, antibodies against human $\alpha$-enolase detected surface enolase on cells of Borrelia burgdorferi ${ }^{30}$ Mycoplasma fermentans ${ }^{31}$ and Pseudomonas aeruginosa. ${ }^{32}$ In studies of Streptococcus agalactiae immunogenic proteins, the bacterial enolase was identified as a protein that reacts with human antibodies from the sera of infected patients. ${ }^{33}$ Lundberg et al. demonstrated that antibodies from the serum of rheumatoid arthritis (RA) patients showed cross-reactivity between citrullinated human $\alpha$-enolase and recombinant citrullinated enolase from Porphyromonas gingivalis. ${ }^{34}$ Moreover, Witkowska et al. demonstrated the immunoreactivity of the 45-kDa OMPs isolated from K. pneumonia, E. coli, Citrobacter, and Hafnia membranes with patient antibodies and also with rabbit anti-human $\beta$-enolase antibodies. ${ }^{12}$ Mass spectrometry analyses of $K$. pneumoniae enolase-like protein showed that several fragments of the $45-\mathrm{kD}$ a protein were found to have sequences identical to the C-terminal domain of human $\beta$-enolase. Additionally, it has been reported that Salmonella membrane proteins with a range of 44-55 kDa were recognized by IgM antibodies from the serum samples of healthy patients and patients with Buerger's disease or psoriasis. ${ }^{12}$ Among several Enerobacteriaceae species, only Salmonella protein of 44-55 kDa has been recognized by IgM antibodies. These results suggest that this protein may serve as a marker for the early phase of infection or recurrence as a result of a bacterial carrier state. The development of reactive arthritis is closely associated with infection of several Gram-negative enteric bacteria, including Salmonella. ${ }^{35}$ Some patients with ulcerative colitis have higher odds of previous infection with Salmonella as well as E. coli, Campylobacter or Clostridium difficile. ${ }^{36}$ Taken together, these results illustrate a potential link between autoimmune diseases and a history of food poisoning. 
Scanning electron microscopy has corroborated the surface localization of membrane antigens that are reactive with anti-cytosolic enolase antibodies. It has also shown that enolase-like protein is present at the surface in low abundance, localized mostly to the flagella. The surface localization of S. pneumoniae enolase has also been confirmed using SEM. ${ }^{37}$ Moreover, relatively low amounts of surface enolase have been proven to contribute to bacterial pathogenesis. ${ }^{11}$ Enolase identified using SEM has been shown on the surface of Streptococcus suis and Streptococcus pyogenes. ${ }^{27,38}$ Enolase expressed on the surface could be recognized by the host immune system. The many reports of cross-reactivity between antibodies against human and bacterial enolases suggest that pathogen-related enolase may be involved in the development of autoimmune disease.

Our study showed that Salmonella membrane proteins with reactivity to antibodies against human $\alpha$ - and $\beta$-enolase also bound human plasminogen. Interestingly, the enolase isolated from the Salmonella cytosol had no plasminogen-binding capacity. The observed lack of affinity of the $S$. Typhimurium cytosolic enolase to human plasminogen, binding only to the enolase receptor located on the membrane of bacterial cells, suggests some structural differences between the 2 forms of enolase. This may be due to certain interactions of the enolase receptor protein with cell membrane components or to possible post-translational modification targeting the cell surface cytosolic protein. It is also important that the mechanisms leading to the transfer of this protein from the cytoplasm to the cell membrane and partial exposure to the cell surface are unknown. Koebnik et al. reported that the common structural $\beta$-barrel motif present in OMPs of Gram-negative bacteria is formed by a variable amount of transmembrane $\beta$-strands that expose the cell to a long loop available to the extracellular environment. ${ }^{7}$ It is interesting that in the three-dimensional structure of the cytosol, enolase is presented as $C$-terminal $\beta$-barrel domain with $\beta \beta \alpha \alpha(\beta \alpha)_{6}$ topology. As a classic cytosolic protein, enolase has no signal sequence, and no hydrophobic domain has been identified that would allow translocation to the cell membrane and anchoring in it. However, Redlitz et al. postulated that the hydrophobic domain splicing amino acids 33-44 near the $\mathrm{N}$-terminus may serve as an internal signal sequence directing this protein to the cell membrane. Post-translational acylation through the addition of palmitic or myristic acid may be another explanation for the association of enolase with the cell membrane. ${ }^{39}$

Plasminogen binding to enolase on the surface of bacterial cells has been demonstrated for bacteria such as Borrelia burgdorferi, Mycoplasma fermentans and Pseudomonas aeruginosa. ${ }^{30-32}$ However, there are studies that have shown plasminogen binding to the cytosolic fraction of Gram-positive bacteria. ${ }^{37}$ Bacterial interaction with host plasminogen can elicit different effects. For example, in some commensals plasminogen plays a protective role for the intestinal barrier by enhancing bacterial colonization; this mechanism has been described for bacteria from the Bifidobacterium genus. ${ }^{40}$ Plasminogen can also promote invasion through the host tissue. Proteolytic activation of plasminogen results in the formation of plasmin, which degrades extracellular matrix proteins. ${ }^{30}$ Further studies of the interaction between cytosol and membrane enolase obtained from Gram-negative bacteria with plasminogen are needed.

In conclusion, we have demonstrated for the first time the epitope similarity between Salmonella and human enolase. Additionally, we used electron microscopy to identify enolase-like protein on the surface of $S$. Typhimurium. This protein exhibits an affinity for human plasminogen, which indicates that Salmonella membrane enolase could play a role in interactions with host cells. The results of this study provide some insight into the interactions of Salmonella with the host and reveal new aspects of the role of glycolytic enzymes. It has become evident that the dual role of these enzymes is crucial to understanding the invasions and interactions of many pathogens with their hosts. The conservative structure of enolase may be a factor in autoimmune complications after bacterial infection. Further investigations may help to provide a comprehensive picture of these mechanisms.

\section{ORCID iDs}

Paweł Serek (D) https://orcid.org/0000-0002-4685-4373

Iwona Bednarz-Misa (D) https://orcid.org/0000-0001-7244-2017 Jadwiga Pietkiewicz (D) https://orcid.org/0000-0001-5109-5618 Bartłomiej Dudek (D) https://orcid.org/0000-0002-6181-3772 Magdalena Mierzchała-Pasierb (1) https://orcid.org/0000-0001-9640-4883 Katarzyna Jermakow (D) https://orcid.org/0000-0001-9889-4265 Marek Drab (D) https://orcid.org/0000-0002-2771-1692 Andrzej Gamian (D) https://orcid.org/0000-0002-2206-6591

\section{References}

1. Cook J, Jeuland M, Whittington D, et al; DOMI Typhoid Economics Study Group. The cost-effectiveness of typhoid Vi vaccination programs: Calculations for four urban sites in four Asian countries. Vaccine. 2008;26(50):6305-6316. doi:10.1016/j.vaccine.2008.09.040

2. World Health Organization. Food safety. https://www.who.int/newsroom/fact-sheets/detail/food-safety. Accessed June 30, 2020.

3. Popoff MY, Bockemühl J, Gheesling LL. Supplement 2002 (No. 46) to the Kauffmann-White scheme. Res Microbiol. 2004;155(7):568-570. doi:10.1016/j.resmic.2004.04.005

4. World Health Organization. Salmonella (non-typhoidal). https://www. who.int/en/news-room/fact-sheets/detail/salmonella-(non-typhoidal). Accessed June 30, 2020.

5. de Jong HK, Parry CM, van der Poll T, Wiersinga WJ. Host-pathogen interaction in invasive salmonellosis. PLoS Pathog. 2012;8(10): e1002933. doi:10.1371/journal.ppat.1002933

6. Alam J, Kim YC, Choi Y. Potential role of bacterial infection in autoimmune diseases: A new aspect of molecular mimicry. Immune Netw. 2014;14(1):7-13. doi:10.4110/in.2014.14.1.7

7. Koebnik R, Locher KP, Van Gelder P. Structure and function of bacterial outer membrane proteins: Barrels in a nutshell. Mol Microbiol. 2000;37(2):239-253. doi:10.1046/j.1365-2958.2000.01983.x

8. Pancholi V. Multifunctional a-enolase: Its role in diseases. Cell Mol Life Sci. 2001;58(7):902-920. doi:10.1007/PL00000910

9. López-Alemany R, Longstaff C, Hawley S, et al. Inhibition of cell surface mediated plasminogen activation by a monoclonal antibody against alpha-enolase. Am J Hematol. 2003;72(4):234-242. doi:10. 1002/ajh.10299 
10. Díaz-Ramos À, Roig-Borrellas A, García-Melero A, López-Alemany R. a-enolase, a multifunctional protein: Its role on pathophysiological situations. J Biomed Biotechnol. 2012;2012:156795. doi:10.1155/2012/ 156795

11. Kolberg J, Aase A, Bergmann S, et al. Streptococcus pneumoniae enolase is important for plasminogen binding despite low abundance of enolase protein on the bacterial cell surface. Microbiology (Reading). 2006;152(Pt 5):1307-1317. doi:10.1099/mic.0.28747-0

12. Witkowska D, Pietkiewicz J, Szostko B, Danielewicz R, Masłowski L, Gamian A. Antibodies against human muscle enolase recognize a 45-kDa bacterial cell wall outer membrane enolase-like protein. FEMS Immunol Med Microbiol. 2005;45(1):53-62. doi:10.1016/j. femsim.2005.01.005

13. Lis J, Jarząb A, Witkowska D. Molecular mimicry in the etiology of autoimmune diseases. Postepy Hig Med Dosw (Online). 2012;66:475-491. doi:10.5604/17322693.1003484

14. Lee $\mathrm{KH}, \mathrm{Chung} \mathrm{HS}$, Kim HS, et al. Human alpha-enolase from endothelial cells as a target antigen of anti-endothelial cell antibody in Behçet's disease. Arthritis Rheum. 2003;48(7):2025-2035. doi:10.1002/ art.11074

15. Fujii A, Yoneda M, Ito T, et al. Autoantibodies against the amino terminal of a-enolase are a useful diagnostic marker of Hashimoto's encephalopathy. J Neuroimmunol. 2005;162(1-2):130-136. doi:10. 1016/j.jneuroim.2005.02.004

16. Nezos A, Cinoku I, Mavragani CP, Moutsopoulos HM. Antibodies against citrullinated alpha enolase peptides in primary Sjogren's syndrome. Clin Immunol. 2017;183:300-303. doi:10.1016/J.CLIM.2017. 09.012

17. Bednarz-Misa I, Pietkiewicz J, Banaś T, Gamian A. Enolase from Klebsiella pneumoniae and human muscle cells. I. Purification and comparative molecular studies. Adv Clin Exp Med. 2009;18(1):71-78.

18. Wold F. Enolase. In: Boyer PD, ed. The Enzymes, 3rd edition, vol. V. New York, NY, USA: Academic Press; 1971: 499-538.

19. Baranowski T, Wolna E. Enolase from human muscle. Methods Enzymol. 1975;42(C):335-338. doi:10.1016/0076-6879(75)42137-1

20. Laemmli UK. Cleavage of structural proteins during the assembly of the head of bacteriophage T4. Nature. 1970;227(5259):680-685. doi:10.1038/227680a0

21. Bugla-Płoskońska G, Futoma-Kołoch B, Skwara A, Doroszkiewicz W. Use of zwitterionic type of detergent in isolation of Escherichia coli O56 outer membrane proteins improves their two-dimensional electrophoresis (2-DE). Polish J Microbiol. 2009;58(3):205-209.

22. Gromova I. Protein detection in gels by silver staining: A procedure compatible with mass spectrometry. Cell Biol. 2006;4:219-223. doi:10. 1016/B978-012164730-8/50212-4

23. Malinowska A, Kistowski M, Bakun M, et al. Diffprot: Software for non-parametric statistical analysis of differential proteomics data. JProteomics. 2012;75(13):4062-4073. doi:10.1016/J.JPROT.2012.05.030

24. Hodyra-Stefaniak K, Miernikiewicz P, Drapała J, et al. Mammalian host-versus-phage immune response determines phage fate in vivo. Sci Rep. 2015;5:14802. doi:10.1038/srep14802

25. Drab M, Krajniak J, Grzelakowski KP. The new methodology and chemical contrast observation by use of the energy-selective backscattered electron detector. Microsc Microanal. 2016;22(6):1369-1373. doi:10.1017/S1431927616012514
26. Saito N. Purification and properties of bacterial phosphopyruvate hydratase. J Biochem. 1967;61(1):59-69. doi:10.1093/oxfordjournals. jbchem.a128521

27. Esgleas M, Li Y, Hancock MA, Harel J, Dubreuil JD, Gottschalk M. Isolation and characterization of a-enolase, a novel fibronectin-binding protein from Streptococcus suis. Microbiology. 2008;154(9):2668-2679. doi:10.1099/mic.0.2008/017145-0

28. Dannelly HK, Reeves HC. Purification and characterization of enolase from Escherichia coli. Curr Microbiol. 1988;17(5):265-268. doi:10.1007/ BF01571326

29. Lee A, Kim YC, Baek K, et al. Treponema denticola enolase contributes to the production of antibodies against ENO1 but not to the progression of periodontitis. Virulence. 2018;9(1):1263-1272. doi:10.1080 /21505594.2018.1496775

30. Floden AM, Watt JA, Brissette CA. Borrelia burgdorferi enolase is a surface-exposed plasminogen binding protein. PLoS One. 2011; 6(11):e27502. doi:10.1371/journal.pone.0027502

31. Yavlovich A, Rechnitzer H, Rottem S. Alpha-enolase resides on the cell surface of Mycoplasma fermentans and binds plasminogen. Infect Immun. 2007;75(12):5716-5719. doi:10.1128/IAI.01049-07

32. Ceremuga I, Seweryn E, Bednarz-Misa I, et al. Enolase-like protein present on the outer membrane of Pseudomonas aeruginosa binds plasminogen. Folia Microbiol (Praha). 2014;59(5):391-397. doi:10.1007/ s12223-014-0311-9

33. Dobrut A, Brzozowska E, Górska S, et al. Epitopes of immunoreactive proteins of Streptococcus agalactiae: Enolase, inosine 5'-monophosphate dehydrogenase and molecular chaperone GroEL. Front Cell Infect Microbiol. 2018;8:349. doi:10.3389/fcimb.2018.00349

34. Lundberg K, Wegner N, Yucel-Lindberg T, Venables PJ. Periodontitis in RA: The citrullinated enolase connection. Nat Rev Rheumatol. 2010;6(12):727-730. doi:10.1038/nrrheum.2010.139

35. Rohekar S, Tsui FWL, Tsui HW, et al. Symptomatic acute reactive arthritis after an outbreak of salmonella.J Rheumatol. 2008;35(8):1599-1602. http://www.ncbi.nlm.nih.gov/pubmed/18528961. Accessed June 30, 2020.

36. Axelrad JE, Olén $\mathrm{O}$, Askling J, et al. Gastrointestinal infection increases odds of inflammatory bowel disease in a nationwide case-control study. Clin Gastroenterol Hepatol. 2018. doi:10.1016/J.CGH.2018.09.034

37. Bergmann S, Rohde M, Chhatwal GS, Hammerschmidt S. Alpha-enolase of Streptococcus pneumoniae is a plasmin(ogen)-binding protein displayed on the bacterial cell surface. MolMicrobiol. 2001;40(6): 1273-1287. doi:10.1046/j.1365-2958.2001.02448.x

38. Pancholi V, Fischetti VA. Alpha-enolase, a novel strong plasmin(ogen) binding protein on the surface of pathogenic streptococci. J Biol Chem. 1998;273(23):14503-14515. doi:10.1074/jbc.273.23.14503

39. Redlitz A, Fowler BJ, Plow EF, Miles LA. The role of an enolase-related molecule in plasminogen binding to cells. Eur JBiochem. 1995;227(1-2): 407-415. doi:10.1111/j.1432-1033.1995.tb20403.x

40. Candela M, Biagi E, Centanni M, et al. Bifidobacterial enolase, a cell surface receptor for human plasminogen involved in the interaction with the host. Microbiology (Reading). 2009;155(10):3294-3303. doi:10.1099/mic.0.028795-0 